\title{
Distribution of Lactococcus spp. in New York State dairy farms and the association of somatic cell count resolution and bacteriological cure in clinical mastitis samples
}

\author{
J. C. Scillieri Smith, ${ }^{1}$ P. Moroni, ${ }^{2,3}$ C. G. Santisteban, ${ }^{2}$ B. J. Rauch, ${ }^{2}$ P. A. Ospina, ${ }^{2 *}$ and D. V. Nydam ${ }^{2}$ \\ ${ }^{1}$ New York State Department of Agriculture and Markets, Division of Animal Industry, 10B Airline Drive, Albany 12235 \\ ${ }^{2}$ Animal Health Diagnostic Center, Quality Milk Production Services, Department of Population Medicine and Diagnostic Sciences, \\ Cornell University, Ithaca, NY 14853 \\ ${ }^{3}$ Dipartimento di Medicina Veterinaria, Università degli Studi di Milano, via Celoria 10, 20133 Milan, Italy
}

\section{ABSTRACT}

We investigated the distribution of pathogenic non-agalactiae gram-positive, catalase-negative cocci (GPCN) in a convenience sample of New York State dairy farms. Our primary objective with the clinical mastitis (CM) GPCN samples was to evaluate somatic cell count (SCC) resolution and bacteriological cure of Streptococcus dysgalactiae or Streptococcus uberis versus Lactococcus lactis or Lactococcus garvieae in cows that received an approved intramammary treatment. In phase I, we assessed the distribution of the GPCN and SCC resolution. In phase II, we evaluated the SCC resolution and bacteriological cure in CM samples from the 4 farms with the highest prevalence of $L$. lactis or L. garvieae in phase I. In phase I, 8,868 CM and subclinical mastitis (SCM) milk samples were received from 143 farms. The GPCN samples identified by culture were confirmed with MALDI-TOF. From the 473 MALDI-TOF-confirmed GPCN samples, 155 were $S$. dysgalactiae $(33 \%) ; 150$, S. uberis $(32 \%) ; 112$, L. lactis (24\%); 16, L. garvieae (3\%); and 40, other GPCN (8\%). From these, 277 were CM samples and 127 were eligible for the evaluation of SCC resolution, which was defined as $\mathrm{SCC} \leq 200,000$ cells $/ \mathrm{mL}$ in a composite sample 15 to $60 \mathrm{~d}$ post-diagnosis. The odds of SCC resolution in CM samples was evaluated with multivariable logistic regression, and the odds were 6.1 [95\% confidence interval (CI):2.7-13.9] times higher for $S$. dysgalactiae or $S$. uberis compared with $L$. lactis or L. garvieae. In phase II, a total of 1,662 CM and SCM samples were evaluated with microbiological methods as in phase I, of which 211 samples were confirmed by MALDI-TOF: $39 \%$ were $S$. dysgalactiae $(\mathrm{n}=61)$ and $S$. uberis (n $=21) ; 55 \%$, L. lactis $(\mathrm{n}=114)$ and L. garvieae $(\mathrm{n}=$

Received December 21, 2018.

Accepted August 19, 2019.

*Corresponding author: pav5@cornell.edu
2 ); and $6 \%$, other GPCN $(\mathrm{n}=13)$. In total, $168 \mathrm{CM}$ samples were eligible for analysis and 118 were included in the final SCC resolution model. Similar statistical methods as in phase I were performed, and the odds of SCC resolution were 2.4 (95\% CI: 1.1-5.5) times higher for $S$. dysgalactiae or $S$. uberis compared with L. lactis or L. garvieae. Bacteriological cure was defined as having a different or negative culture on a quarter sample taken 14 to $28 \mathrm{~d}$ after initial diagnosis. The odds of bacteriological cure $(\mathrm{n}=121)$ were 8.0 (95\% CI: 2.5-25.6) times higher for $S$. dysgalactiae or $S$. uberis compared with L. lactis or L. garvieae. Differences in SCC resolution and bacteriological cure between these groups may dictate a different management approach.

Key words: gram-positive, catalase-negative cocci, clinical mastitis, MALDI-TOF, Lactococcus spp.

\section{INTRODUCTION}

Mastitis is an expensive disease affecting all farms in the dairy industry. It can cost more than $\$ 444$ per clinical mastitis (CM) case (Rollin et al., 2015) and result in a 2 to $5 \%$ loss of 305 -d milk in the average lactation per subclinical mastitis (SCM) case (HagnestamNielsen et al., 2009). Both SCM and CM can cause an increase in SCC above 200,000 cells/mL (Dohoo et al., 1991), which negatively affects milk production, milk quality, and access to milk quality premiums (Hand et al., 2012a,b). Dairy farmers use a variety of prevention and treatment strategies to reduce the risk of mastitis in their cows (Huijps et al., 2010) to maintain milk production, decrease SCC, improve animal well-being, and increase income. One common strategy has been to treat all CM cases with intramammary (IMM) antimicrobials (Pol and Ruegg, 2007). However, research has raised questions about the economic viability of this approach, noting that pathogen-specific treatment targeting bacteria more likely to respond to IMM antimicrobials can decrease the treatment and milk-discard 
costs (MacDonald et al., 2011). Farms that adopted the strategy to use IMM antimicrobials in CM cases associated with gram-positive bacterial growth and not treat those with either gram-negative or no growth did not see a difference in cure rates (Keefe et al., 2010) or other CM-relevant outcomes such as recurrence, days to clinical cure, culling, or milk production (Lago et al., 2011a,b; Vasquez et al., 2017). As the focus of IMM antimicrobials narrows to gram-positive pathogens in CM samples (Oliver et al., 2004), understanding the distribution of these pathogens is a priority.

Recent research on the prevalence of mastitis pathogens at 5 farms in New York State (Hertl et al., 2014) reported that Streptococcus spp. represented the most common pathogen type associated with $\mathrm{CM}$, with a prevalence of $22 \%$ of first cases, $18 \%$ of second cases, and $14 \%$ of third cases in a cow's lactation. Vasquez et al. $(2016,2017)$ also reported a high proportion of Streptococcus spp. in CM samples in New York dairy farms. This distribution is not unique to New York, and streptococci are commonly isolated from cow's milk with CM in Belgium (Verbeke et al., 2014), New Zealand (McDougall, 2003), Australia (Shum et al., 2009), Canada (Olde Riekerink et al., 2008), Italy (Ospina et al., 2016), and the United Kingdom (Bradley et al., 2007).

Although identification of Streptococcus agalactiae and Streptococcus dysgalactiae is very accurate with standard microbiological methods (Wyder et al., 2011; Raemy et al., 2013), common biochemical tests cannot easily differentiate Streptococcus spp. from the remaining non-agalactiae gram-positive, catalase-negative cocci (GPCN), including species in the genera Lactococcus, Enterococcus, and Aerococcus. Consequently, these bacteria are misidentified 31 to $77 \%$ of the time (Fortin et al., 2003). Although the frequency of infection can vary between herds, GPCN can account for as much as $45 \%$ of IMM infections (Todhunter et al., 1995; Jones and Swisher, 2009; Hertl et al., 2014). In milk samples from CM and SCM cases, Lactococcus lactis, Aerococcus viridans, and Streptococcus parauberis pathogens were also difficult to differentiate phenotypically from other Streptococcus spp., indicating that these pathogens are likely to be misidentified and unreported as a potential cause of CM and SCM cases (Werner et al., 2014). Previous reports evaluating the prevalence of Lactococcus spp. found low levels of infection in SCM samples (3\%, Haguingan et al., 2010; 7\%, Devriese et al., 1999) and on a whole population level (0.9\%, Wyder et al., 2011). As a result, these less common pathogens, such as Lactococcus spp., have been frequently grouped together as "Streptococcus species" or are misidentified as Streptococcus uberis, making it difficult to assess the significance of these unique organisms (Devriese et al., 1999; Fortin et al., 2003; Odierno et al., 2006). Compared with phenotypic methods and 16S rRNA sequencing, newer technology, such as MALDI-TOF (Randall et al., 2015), has been used to confirm the identification of many of these GPCN. Furthermore, Lactococcus spp. are common pathogens on some farms (Plumed-Ferrer et al., 2013; Werner et al., 2014; Plumed-Ferrer et al., 2015; Rodrigues et al., 2016), warranting additional research into these organisms.

In the current study, our objectives were (1) to describe the distribution of GPCN in CM and SCM milk samples based on MALDI-TOF identification in a convenience sample of New York dairy farms; (2) to compare DHIA SCC resolution for CM samples with S. dysgalactiae or S. uberis versus L. lactis or L. garvieae in CM samples that received an approved IMM antimicrobial; and (3) to evaluate SCC resolution and bacteriological cure in CM samples that received an approved IMM mastitis treatment and had $S$. dysgalactiae or S. uberis versus L. lactis or L. garvieae at farms with a high prevalence of Lactococcus spp.

\section{MATERIALS AND METHODS}

\section{Sample Collection}

Aseptic Milk Samples. Milk samples were aseptically collected by trained on-farm personnel or Quality Milk Production Services (QMPS) at Cornell University College of Veterinary Medicine staff and kept cool $\left(1^{\circ} \mathrm{C}\right)$ or frozen $\left(-20^{\circ} \mathrm{C}\right)$ until reaching either the QMPS laboratory in Canton, NY, or the Veterinary Clinic in Lowville, NY. These samples were then processed through MALDI-TOF for confirmation. This observational data set consisted of a convenience sample of quarter and composite milk samples from both CM and SCM cases as identified by farm personnel. The CM samples were collected from cows identified by farm personnel as having abnormal milk (e.g., clots, watery milk, blood), with or without changes to the udder. All cows with CM received an approved IMM antimicrobial based on farm protocols. The SCM samples included fresh cow screening, cows sampled due to high SCC, and whole herd sampling performed by QMPS technicians.

Composite SCC Sample Collection and Evaluation. Farms were enrolled in routine whole herd DHIA testing. Briefly, on test day, trained DHIA technicians obtained about 40 to $75 \mathrm{~mL}$ of individual composite milk samples at the time of milking from a portable metered sampler that is verified annually. The milk sample 
was preserved with DHI milk preservative, which has an active ingredient of 18\% 2-bromo-2- nitropropane-1, 3-diol (Bronopol-Boots, National DHIA, Columbus, $\mathrm{OH}$ ), at the mandated $2.05 \mu \mathrm{L}$ of preservative per 40 to $75 \mathrm{~mL}$ of milk sample. The samples were kept at ambient temperature or refrigerated to ensure they were not exposed to temperature extremes. The milk samples were then tested for SCC at DHIA (Dairy One, Ithaca, NY) using flow cytometry (Fossomatic, Foss, Hillerød, Denmark). Milk samples collected 15 to $60 \mathrm{~d}$ after CM diagnosis were included in the analysis.

\section{Pathogen Identification}

A sterile 15-cm wood-handled cotton swab (Puritan Medical Products Co., Guilford, ME; cotton swab dimensions 16 by $5 \mathrm{~mm}$ ) was used to take the milk sample from the vial and used to streak one half of a trypticase soy agar plate containing 5\% sheep blood and $0.1 \%$ esculin (Hardy Diagnostics, Santa Maria, CA) with approximately $30 \mu \mathrm{L}$ of milk. Plates were incubated aerobically at $37^{\circ} \mathrm{C}$ for $24 \mathrm{~h}$ (National Mastitis Council, 2017). At $24 \mathrm{~h}$, initial phenotypic identification based on colony morphology was performed to select for presumptive GPCN. Plates with at least 3 GPCN colonies were included in additional evaluation. An esculin hydrolysis reaction was evaluated. Esculin-negative colonies were further evaluated with Lancefield grouping PathoDx group C (Inzana and Iritani, 1989) and Christie-Atkins-Munch-Petersen factor test if necessary. Esculin-positive colonies were inoculated on bile esculin medium (Becton, Dickinson and Company, Sparks, MD). A single representative colony, excluding $S$. agalactiae, from the original plates was replated on blood agar and incubated for $24 \mathrm{~h}$, after which a representative colony was evaluated with MALDI-TOF (Randall et al., 2015). The MALDI-TOF evaluation was done at the Ithaca QMPS laboratory. A $\log$ (score) $\geq 1.7$ was the threshold for the genus-level identification and a $\log$ (score) of $\geq 2.0$ was the set as the threshold for a match at the species level. Only samples identified to the species level were retained for further analysis.

\section{Statistical Analysis}

All data were compiled in Excel software (Microsoft Corp., Santa Rosa, CA) and imported into SAS 9.4 (SAS Institute Inc., Cary, NC) for statistical analysis. Three 3 models were evaluated in this prospective cohort study.

In phase I, the distribution of pathogenic GPCN in $\mathrm{CM}$ and SCM was described and the association between SCC resolution and pathogen group was evalu- ated in CM samples. In phase II, the distribution of pathogenic GPCN in CM samples from selected herds was also described. Two independent models were constructed to evaluate SCC resolution and bacteriological cure in CM samples. The risk difference between the unexposed (samples with $S$. dysgalactiae or S. uberis) versus the exposed (samples with L. lactis or L. garvieae) was estimated by subtracting 2 proportions. The proportions consisted of the number of samples with SCC resolution in phase I and II and bacteriological cure in phase II, each divided by the total number of samples from the exposed and exposed groups, respectively.

In these prospective cohort studies, cows entered the study when they were diagnosed with CM. They were then followed forward in time, and the association between the outcome of interest (i.e., SCC resolution or bacteriological cure) and the exposure (i.e., diagnosis with $S$. dysgalactiae or $S$. uberis versus $L$. lactis or $L$. garvieae) was evaluated. Based on a DHIA composite milk sample, collected 15 to $60 \mathrm{~d}$ after CM diagnosis, the SCC resolution (in both phase I and II) was defined if SCC was $\leq 200,000$ cells $/ \mathrm{mL}$. Bacteriological cure (in phase II) was defined as a follow-up sample collected 14 to $28 \mathrm{~d}$ after $\mathrm{CM}$ diagnosis with the culture result being negative or showing the presence of a different pathogen. Throughout the study, the farm did not receive information regarding pathogen diagnosis before treatment, thus minimizing potential for systematic treatment bias based on pathogen.

Phase I Inclusion Criteria. To be included in the final analysis of phase I, the following criteria needed to be met: initial CM quarter-level sample, cow present for a follow-up DHIA sample between 15 and $60 \mathrm{~d}$ after $\mathrm{CM}$ diagnosis, and record of the cow having received an approved IMM antimicrobial treatment. Of the 277 CM samples available for analysis, the following were excluded: 49 were dropped because the original samples were composite samples; 76 were missing information about when the DHIA sample was collected or missing DHIA data; 5 were collected less than 2 wk after CM diagnosis; 9 were missing treatment information; and 11 contained a pathogen that was not one of the top pathogens (i.e., S. dysgalactiae, S. uberis, L. lactis, or L. garvieae). Thus, 127 samples from 10 farms were available for final analysis of SCC resolution in phase I (Figure 1).

Phase II Inclusion Criteria for SCC Resolution. To be included in the final analysis in the evaluation of SCC resolution in phase II, the following criteria needed to be met: initial CM quarter-level sample, cow present for a follow-up DHIA sample between 15 and $60 \mathrm{~d}$ after CM diagnosis, and record of the cow having received an approved IMM antimicrobial treatment. 
Of the 168 cows sampled for CM, the following were excluded from the final analysis: 10 did not include one of thetwo pathogen groups $(S$. dysgalactiae or $S$. uberis versus $L$. lactis or $L$. garvieae), 6 initial CM milk samples were not quarter samples, 8 did not have IMM treatment information, and 26 were missing DHIA data. Thus, 118 samples were available for SCC resolution analysis in phase II (Figure 2).

Phase II Inclusion Criteria for Bacteriological Cure. To be included in the final analysis for bacteriological cure, the following criteria needed to be met: initial CM quarter-level sample, cow present for a follow-up quarter-level sample 14 to $28 \mathrm{~d}$ after $\mathrm{CM}$ diagnosis, and record of the cow having received an approved IMM antimicrobial treatment. From the 168 samples from cows with CM identified in phase II, the following were excluded from analysis: 10 did not include one of the top 2 pathogen groups, 6 did not originate from quarter samples, 8 did not have IMM treatment information (either none or unknown), and 23 did not have information about an outcome. Thus, 121 samples were eligible for bacteriological cure (Figure 2).

8,534 aseptically collected clinical mastitis (CM), subclinical (SCM), and milk samples without additional information were processed by the Quality Milk Production Services (QMPS) laboratory in Canton, NY, and 334 were processed at a veterinary clinic in Lowville, NY. These samples originated from 143 farms.

495 of these milk samples were identified as having grampositive catalase-negative (GPCN) culture results with standard microbiological techniques.

These milk samples were submitted to the QMPS laboratory in Ithaca for MALDI-TOF evaluation.

22 samples were removed from further analysis because species-level identification was not confirmed (MALDI-TOF score $<2.0$ )

473 milk samples:

$277 \mathrm{CM}, 126 \mathrm{SCM}$, and 70 had no additional

150 of these $\mathrm{CM}$ samples were not included in final analysis because they did not meet the inclusion criteria

$127 \mathrm{CM}$ samples were available for final analysis of SCC resolution in phase $\mathrm{I}$.

These samples originated from 10 farms.

Figure 1. Flow diagram of samples included in final analysis of SCC resolution model in phase I (May to November 2014).

\section{Models}

The GLIMMIX procedure (SAS v. 9.4) was used to model the odds of SCC resolution in phase I and the independent odds of SCC resolution and bacteriological cure in phase II. In all models, a manual backward stepwise elimination strategy with farm as a random effect was used. Variables and interactions starting with $P>0.25$ were eliminated, until only covariates with $P \leq 0.05$ remained in the final model. The following continuous variables were categorized to facilitate interpretation: parity, DIM at CM diagnosis, and number of days from CM diagnosis to DHIA testing. Parity was categorized into 2 groups: lactation $=1$ and lactation $\geq 2$. The DIM at CM diagnosis was categorized into 3 groups: early (1-30 DIM), mid lactation (31-180 DIM), and late lactation $(>180$ DIM). The number of days from CM diagnosis to DHIA testing was categorized into 3 groups: 15 to $30 \mathrm{~d}, 31$ to $45 \mathrm{~d}$, and 46 to $60 \mathrm{~d}$. This variable was included only in the SCC resolution models.

SCC Resolution. In phases I and II, the initial multivariable models included pathogen group $(S$. dysgalactiae or $S$. uberis versus $L$. lactis or $L$. garvieae), parity group, DIM at diagnosis category, number of days from CM diagnosis to DHIA testing category, and the following interactions: pathogen group $\times$ parity group, and pathogen group $\times$ number of days from $\mathrm{CM}$ diagnosis to DHIA testing category.

In phase I, 127 samples were eligible for analysis. Parity groups 1 and 2 had 34 and 93 cows, respectively. Twenty-two cows were in early lactation, 46 were in mid lactation, and 59 were in late lactation. The number of days from CM to DHIA testing included 47 cows sampled at 15 to $30 \mathrm{~d}, 42$ at 31 to $45 \mathrm{~d}$, and 38 at 46 to $60 \mathrm{~d}$. In phase I, the final model included only pathogen group (S. dysgalactiae or $S$. uberis versus $L$. lactis or $L$. garvieae) and farm as a random effect.

In phase II, 118 samples were eligible for analysis. Parity groups 1 and 2 had 20 and 98 cows, respectively. Eleven cows were in early lactation, 58 were in mid lactation, and 49 were in late lactation. The number of days from CM to DHIA testing included 64 cows sampled at 15 to $30 \mathrm{~d}, 40$ at 31 to $45 \mathrm{~d}$, and 14 at 46 to $60 \mathrm{~d}$. In phase II, the final model evaluating SCC resolution included only the pathogen group $(S$. dysgalactiae or S. uberis versus L. lactis or L. garvieae) and farm as a random effect.

Bacteriological Cure. For the bacteriological cure model, the initial model included pathogen group, DIM-at-diagnosis group, parity group, and the interaction of pathogen group $\times$ parity group. Among the 121 samples available for analysis, 28 cows were in 
1,662 ascptically collected clinical mastitis (CM) and subclinical (SCM)

milk samples were processed by the Quality Milk Production Services

(QMPS) laboratory in Canton, NY, for phase II.

These samples originated from 4 farms identified in phase I as having

9 or more Lacto. spp. in both CM and SCM samples.

247 of these milk samples were identified as having gram-positive

catalase-negative (GPCN) culture results with standard

microbiological techniques.

These milk samples were submitted to the QMPS laboratory in Ithaca

for MALDI-TOF evaluation.

1 sample removed based on MALDI identification of non-GPCN pathogen.

31 were removed from further analysis because species-level identification was not confirmed (MALDI score $<2.0$ ).

4 removed because they were sampled within $14 \mathrm{~d}$ of a previous CM event.

211 milk samples:

$168 \mathrm{CM}$ and $43 \mathrm{SCM}$

SCC cure in phase II: $50 \mathrm{CM}$ samples were excluded from the final analysis because they did not mect the inclusion criteria.

118 CM samples were included in the final analysis of SCC resolution in phase II.
Bacteriological cure in phase II: $47 \mathrm{CM}$ samples were excluded from the final analysis because they did not meet the inclusion criteria.

121 CM samples were included in the final analysis of bacteriological curc in phase II.

Figure 2. Flow diagram of samples included in the final analysis of SCC resolution and bacteriological cure in phase II (April to October 2015).

parity group 1 and 93 were in group 2 , and the DIM at diagnosis included 13 cows in early lactation, 59 in mid lactation, and 49 in late lactation. The final model included only the pathogen group $(S$. dysgalactiae or $S$. uberis vs. L. lactis or L. garvieae) and farm as a random effect.

\section{RESULTS}

\section{Phase I}

Distribution of GPCN. The distribution of the GPCN in the 473 samples from CM and SCM milk samples from phase I is found in Table 1 . Table 2 describes the distribution of pathogenic GPCN from farms in phase I with 10 or more CM samples. Most (214 of 277 ) of the CM samples originated from 6 farms with an average herd size of 1,120 (range 500-1,975). From these 6 farms, one pathogen group was cultured in the majority (at least 54\%) of the CM samples. Three of the 6 farms had Lactococcus spp. as the major pathogen in CM samples, while 2 farms had $S$. dysgalactiae and 1 farm had S. uberis as the major pathogenic GPCN.

$S C C$ Resolution (SCC $<200,000$ cells $/ m L)$ in Composite Milk Samples. In phase I, which included $127 \mathrm{CM}$ samples available for analysis, 73 samples were found to contain S. dysgalactiae or S. uberis ( $68 \%$ with SCC resolution) and 54 had L. lactis or L. garvieae (26\% with SCC resolution), with a risk difference of $40 \%$. In these 127 composite milk samples, irrespective of SCC resolution status, the mean linear score was 3.3 for samples with a $S$. dysgalactiae or $S$. uberis culture result and 5.0 for those with L. lactis or L. garvieae. Cows with CM and S. dysgalactiae or S. uberis identified in the sample had higher odds (6.1) of a SCC resolution than those with L. lactis or L. garvieae (Table 3). 
Table 1. Distribution of gram-positive, catalase-negative cocci (GPCN) identified by MALDI-TOF in milk samples originating from 92 New York State dairy farms from May to November 2014 during phase $\mathrm{I}^{1}$ of the study

\begin{tabular}{|c|c|c|c|c|c|}
\hline Organism & $\mathrm{CM}^{2}$ & $\mathrm{SCM}^{3}$ & $\begin{array}{l}\text { Unknown } \\
\text { reason }\end{array}$ & Total & $\begin{array}{l}\% \text { of cases } \\
\text { (from } 473 \text { ) }\end{array}$ \\
\hline Aerococcus viridans & - & 2 & - & 2 & 0.4 \\
\hline Enterococcus casseliflavus & 1 & - & - & 1 & 0.2 \\
\hline Enterococcus faecalis & 1 & 1 & 1 & 3 & 0.6 \\
\hline Enterococcus faecium & 1 & - & - & 1 & 0.2 \\
\hline Enterococcus saccharolyticus & 15 & 7 & - & 22 & 4.7 \\
\hline Lactococcus garvieae & 6 & 8 & 2 & 16 & 3.4 \\
\hline Lactococcus lactis & 91 & 18 & 3 & 112 & 23.7 \\
\hline Streptococcus dysgalactiae & 113 & 23 & 19 & 155 & 32.8 \\
\hline Streptococcus gallolyticus & 2 & 4 & - & 6 & 1.3 \\
\hline Streptococcus oralis & 1 & - & - & 1 & 0.2 \\
\hline Streptococcus parauberis & 1 & 1 & 1 & 3 & 0.6 \\
\hline Streptococcus suis & 1 & - & - & 1 & 0.2 \\
\hline Streptococcus uberis & 44 & 62 & 44 & 150 & 31.7 \\
\hline Total & 277 & 126 & 70 & 473 & 100 \\
\hline
\end{tabular}

${ }^{1}$ During phase I, a convenience sample of 8,868 milk samples (including clinical mastitis, subclinical mastitis, and those sampled for unknown reasons) were evaluated through culture; 495 were identified as having GPCN. Of these, 473 were confirmed by MALDI-TOF with a score of $\geq 2.0$.

${ }^{2}$ Trained on-farm personnel diagnosed clinical mastitis $(\mathrm{CM})$ cases cow-side based on the presence of abnormal milk.

${ }^{3}$ Subclinical mastitis (SCM) cases include those sampled as fresh cows for routine screening $(\mathrm{n}=10)$, those sampled during whole-herd samplings screening for contagious pathogens $(\mathrm{n}=101)$, and those sampled due to high SCC after DHIA testing $(\mathrm{n}=15)$.

\section{Phase II}

Distribution of GPCN. Table 4 shows the distribution of GPCN in the $168 \mathrm{CM}$ samples from the 4 farms. Farms A to D are the same farms found in Table 2. Farm size ranged from 500 to 2,300 lactating cows, all of which were housed in freestall barns. Three of the
4 farms had Lactococcus spp. as the major pathogen in CM samples and the remaining farm had S. dysgalactiae as the major pathogenic GPCN.

$S C C$ Resolution (SCC $\leq 200,000$ cells $/ m L$ ) in Composite Milk Samples. Among the 118 samples available for analysis, 52 samples contained $S$. dysgalactiae or S. uberis (65\% with SCC resolution) and 66 had

Table 2. Distribution of gram-positive, catalase-negative cocci (GPCN) from New York State dairy farms with 10 or more positive clinical mastitis ${ }^{1}$ samples submitted from May to November 2014 during phase $\mathrm{I}^{2}$ of the study

GPCN count of samples (\% of total samples by farm $\pm 95 \% \mathrm{CI}$ )

\begin{tabular}{lccccc}
\cline { 2 - 4 } Farm & $\begin{array}{c}\text { Streptococcus } \\
\text { dysgalactiae }\end{array}$ & $\begin{array}{c}\text { Streptococcus } \\
\text { uberis }\end{array}$ & Lactococcus spp. $^{3}$ & Other $^{4}$ & $\begin{array}{c}\text { Total no. } \\
\text { of samples }\end{array}$ \\
\hline $\mathrm{A}$ & $15(19 \pm 9)$ & $7(9 \pm 6)$ & $49(62 \pm 11)^{5}$ & $8(10 \pm 7)$ & 79 \\
$\mathrm{~B}$ & $7(26 \pm 17)$ & $1(4 \pm 7)$ & $18(67 \pm 18)^{5}$ & $1(4 \pm 7)$ & 27 \\
$\mathrm{C}$ & $15(58 \pm 19)^{5}$ & $1(4 \pm 7)$ & $9(34 \pm 18)$ & $1(4 \pm 7)$ & 26 \\
$\mathrm{D}$ & $5(26 \pm 19)$ & $1(5 \pm 10)$ & $12(60 \pm 21)^{5}$ & $2(10 \pm 13)$ & 20 \\
$\mathrm{E}$ & $43(88 \pm 9)^{5}$ & $4(8 \pm 8)$ & $0(0)$ & $2(4 \pm 6)$ & 49 \\
$\mathrm{~F}$ & $4(30 \pm 25)$ & $7(54 \pm 27)^{5}$ & $0(0)$ & $2(15 \pm 20)$ & 13 \\
Total & 89 & 21 & 88 & 16 & 214
\end{tabular}

${ }^{1}$ Trained on-farm personnel diagnosed clinical mastitis (CM) cases cow-side based on the presence of abnormal milk.

${ }^{2}$ During phase I, a convenience sample of 143 farms submitted 8,868 milk samples (including clinical mastitis, subclinical, and those sampled for unknown reasons), which were evaluated through culture; 495 were identified as having GPCN. From these, 473 were confirmed by MALDI-TOF with a score of $\geq 2.0$. The confirmed samples included $277 \mathrm{CM}$ samples, 214 of which originated from these 6 farms.

${ }^{3}$ Includes Lactococcus lactis $(\mathrm{n}=84)$ and Lactococcus garvieae $(\mathrm{n}=4)$.

${ }^{4}$ Includes Streptococcus suis $(\mathrm{n}=1)$, Streptococcus gallolyticus $(\mathrm{n}=2)$, Streptococcus parauberis $(\mathrm{n}=1)$, Enterococcus saccharolyticus $(\mathrm{n}=10)$, Enterococcus faecium $(\mathrm{n}=1)$, and Enterococcus casseliflavus $(\mathrm{n}=1)$.

${ }^{5}$ The most commonly isolated pathogen by farm. 
Table 3. The odds of $\mathrm{SCC}^{1}$ resolution by pathogen group ${ }^{2}$ in clinical mastitis $(\mathrm{CM})^{3}$ milk samples $(\mathrm{n}=127)$ from 10 farms $^{4}$ during May to November 2014 during phase $I^{5}$ of the study

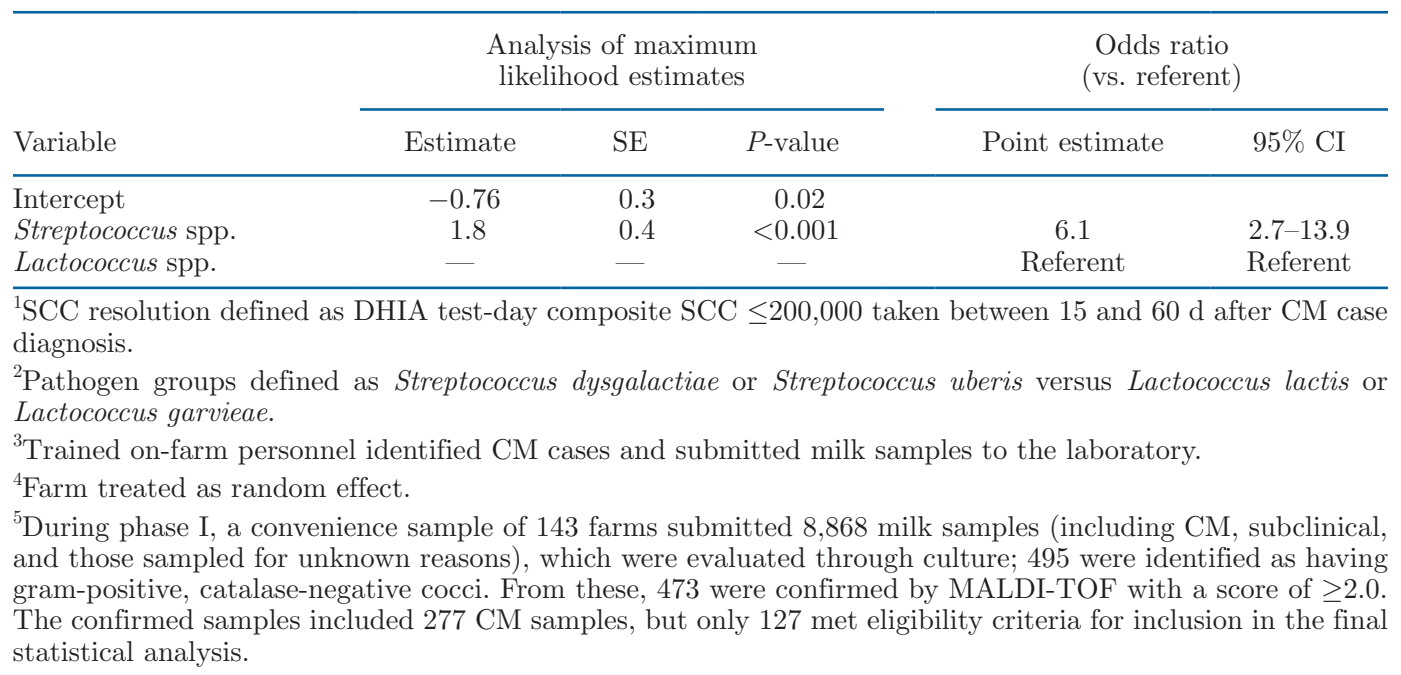

L. lactis or L. garvieae (48\% with SCC resolution), with a risk difference of $17 \%$. In these 118 composite milk samples, the mean linear score was 5.2 for samples with S. dysgalactiae or S. uberis culture results and 6.3 for those with L. lactis or L. garvieae. Cows with CM and $S$. dysgalactiae or $S$. uberis culture result had higher odds (2.4) of a SCC resolution than those with L. lactis or L. garvieae (Table 5).

Bacteriological Cure in CM Samples. Among the 121 samples available for bacteriological analysis, 57 samples contained S. dysgalactiae or S. uberis $(93 \%$ bacteriological cures) and 64 had L. lactis or L. garvieae (63\% with bacteriological cures), with a risk difference of $30 \%$. The odds of a cow experiencing a bacteriologi- cal cure was higher (8.0) if $S$. dysgalactiae or S. uberis was present versus $L$. lactis or L. garvieae (Table 6).

\section{DISCUSSION}

We evaluated the presence of Lactococcus spp. in both CM and SCM samples from multiple commercial farms in this study, thus helping to define the distribution of this pathogen and its relationship with other pathogenic GPCN in these sample types. Although the sampling scheme for phase I was based on a convenience sample of 143 farms in northern New York and was not balanced for farm size, location, or other potential confounders, these samples were representative

Table 4. The distribution of gram-positive, catalase-negative cocci (GPCN) in clinical mastitis (CM) ${ }^{1}$ samples from the 4 farms selected to be part of phase $\mathrm{II}^{2}$ of the study (samples submitted from April to October 2015)

\begin{tabular}{lccccc}
\hline & \multicolumn{2}{c}{ GPCN count of samples (\% of total samples by farm $\pm 95 \%$ CI) } & \\
\cline { 2 - 5 } & $\begin{array}{c}\text { Streptococcus } \\
\text { dysgalactiae }\end{array}$ & $\begin{array}{c}\text { Streptococcus } \\
\text { uberis }\end{array}$ & Lactococcus spp. $^{4}$ & Other & No. of \\
Farm & & & \\
\hline $\mathrm{A}$ & $15(27 \pm 12)$ & $2(4 \pm 5)$ & $32(57 \pm 13)^{6}$ & $7(13 \pm 9)$ & 56 \\
$\mathrm{~B}$ & $10(59 \pm 23)^{6}$ & $0(0)$ & $7(41 \pm 23)$ & $0(0)$ & 17 \\
$\mathrm{C}$ & $13(24 \pm 11)$ & $11(20 \pm 11)$ & $29(53 \pm 13)^{6}$ & $2(3 \pm 5)$ & 55 \\
D & $14(35 \pm 15)$ & $5(12.5 \pm 10)$ & $20(50 \pm 15)^{6}$ & $1(2.5 \pm 5)$ & 40 \\
Total & 52 & 18 & 88 & 10 & 168 \\
\hline
\end{tabular}

${ }^{1} \mathrm{CM}$ identified by presence of abnormal milk by trained on-farm personnel. All CM samples were submitted by the farm for evaluation.

${ }^{2}$ Farms with 9 or more Lactococcus spp. from either CM or subclinical CM samples in phase I were selected to be part of phase II.

${ }^{3}$ Farms (A-D) in this table are the same farms included in Table 2 and are presented in the same order.

${ }^{4}$ Lactococcus lactis $(\mathrm{n}=87)$ and Lactococcus garvieae $(\mathrm{n}=1)$.

${ }^{5}$ Includes Enterococcus saccharolyticus $(\mathrm{n}=6)$, Enterococcus faecium $(\mathrm{n}=1)$, Enterococcus thailandicus $(\mathrm{n}=$ 1), Streptococcus equinus $(\mathrm{n}=1)$, and Streptococcus mitis $(\mathrm{n}=1)$.

${ }^{6}$ The most commonly isolated pathogen by farm. 
Table 5. The odds of SCC resolution ${ }^{1}$ by pathogen group ${ }^{2}$ in clinical mastitis $(\mathrm{CM})^{3}$ milk samples $(\mathrm{n}=118)$ from 4 farms ${ }^{4}$ in phase $\mathrm{II}^{5}$

\begin{tabular}{|c|c|c|c|c|c|}
\hline \multirow[b]{2}{*}{ Variable } & \multicolumn{3}{|c|}{$\begin{array}{l}\text { Analysis of maximum } \\
\text { likelihood estimates }\end{array}$} & \multicolumn{2}{|c|}{ Odds ratio (vs. referent) } \\
\hline & Estimate & $\mathrm{SE}$ & $P$-value & Point estimate & $95 \% \mathrm{CI}$ \\
\hline Intercept & -0.1 & 0.5 & 0.9 & & \\
\hline Streptococcus spp. & 0.9 & 0.4 & 0.03 & 2.4 & $1.1-5.5$ \\
\hline Lactococcus spp. & - & - & - & Referent & Referent \\
\hline \multicolumn{6}{|c|}{$\begin{array}{l}{ }^{1} \text { SCC resolution defined as DHIA test-day composite SCC } \leq 200,000 \text { taken between } 15 \text { and } 60 \mathrm{~d} \text { after CM cas } \\
\text { diagnosis. }\end{array}$} \\
\hline \multicolumn{6}{|c|}{$\begin{array}{l}{ }^{2} \text { Pathogen groups defined as Streptococcus dysgalactiae or Streptococcus uberis versus Lactococcus lactis o } \\
\text { Lactococcus garvieae. }\end{array}$} \\
\hline \multicolumn{6}{|c|}{${ }^{3}$ Trained on-farm personnel identified CM cases and submitted milk samples to the laboratory. } \\
\hline \multicolumn{6}{|c|}{${ }^{4}$ Farm treated as random effect. } \\
\hline \multicolumn{6}{|c|}{$\begin{array}{l}{ }^{5} \text { Farms with } 9 \text { or more Lactococcus spp. from either CM or subclinical CM samples in phase I were selected to } \\
\text { be part of phase II. }\end{array}$} \\
\hline
\end{tabular}

of those received by the Canton QMPS laboratory and the veterinary clinic during the study period. We found that Lactococcus spp. could be commonly isolated in both CM and SCM samples, accounting for up to $27 \%$ of all GPCN cases, Table 1.

Lactococcus spp. have recently been referred to as emerging pathogens in CM (Rodrigues et al., 2016). Their emergence as pathogenic species could be related to changes in the environment that facilitate their growth and introduction into the udder or to improved biochemical and advanced molecular techniques in milk quality laboratories enabling accurate identification of Lactococcus spp. instead of misclassification as Streptococcus spp. (Werner et al., 2014). Given that Streptococcus spp. are among the most commonly isolated pathogens in CM samples (Hertl et al., 2014; Oliviera and Ruegg, 2014; Vasquez et al., 2017), it may not be surprising that the use of molecular techniques (e.g., MALDI-TOF) to confirm pathogen identify in our study revealed, for example, that Lactococcus spp. were present in $35 \%$ of CM cases in phase I (Table 1). The odds of SCC resolution were 6.1 (95\% CI: 2.7-13.9; Table 3) times higher in phase I, in which a convenience sample of dairy herds was evaluated, and 2.4 (95\% CI: 1.1-5.5; Table 5) times higher in the 4 herds selected for having a high prevalence of Lactococcus spp. for samples with $S$. dysgalactiae or S. uberis compared with L. lactis or L. garvieae. The odds of bacteriological cure was 8.0 (95\% CI: 2.5-25.6; Table 6) higher for samples with $S$. dysgalactiae or S. uberis compared with $L$. lactis or L. garvieae in phase II. Due to the differences in SCC resolution and bacteriological cure, proper identification of the causal pathogen in infections is important because cases may be managed differently based on the organism.

As reported, the odds of SCC resolution and bacteriological cure were higher for cows with $S$. dysgalactiae or $S$. uberis culture results compared with L. lactis or L. garvieae, albeit with some limitations. The SCC was based on a composite DHIA milk sample that can be

Table 6. The odds of bacteriological cure ${ }^{1}$ by pathogen group ${ }^{2}$ in clinical mastitis $(\mathrm{CM})^{3}$ milk samples $(\mathrm{n}=$ 121) from 4 farms ${ }^{4}$ in phase $\mathrm{II}^{5}$

\begin{tabular}{l}
\hline \\
\cline { 2 - 5 }
\end{tabular}


affected by other quarters. Additionally, initial SCC evaluation was not done for CM samples. However, it is important to note that SCC resolution was defined as $\mathrm{SCC} \leq 200,000$ cells $/ \mathrm{mL}$ in a composite milk sample. It was defined in this manner to avoid confusing it with a cure, which would have required an initial sample. From a management perspective, farms use the composite SCC to make management decisions for specific cows in a herd, and it is still a useful outcome to measure. In both phase I and II, only CM cases that received an approved IMM antibiotic for mastitis treatment were included in the final analysis. However, sample size was not sufficient to compare the effectiveness of treatment choice or duration. Randomized controlled trials evaluating the effectiveness of certain IMM treatments and durations are necessary to accurately answer this question. Lastly, the statistical analysis focused on comparing 2 pathogen groups composed of L. lactis and $L$. garvieae in one group and $S$. dysgalactiae and $S$. uberis in the other; the analysis did not evaluate any potential differences between the species within each group. Evaluation at this level was not possible due to the small number of eligible $S$. uberis and L. garvieae. Future studies could balance the data set to include a sufficient number of $S$. uberis for a separate analysis given that this species has also been shown to result in persistent infections (Oliver et al., 2004; Milne et al., 2005).

One reason for initiating this project was to seek answers to producer-driven questions about where Lactococcus spp. were coming from and why they seemed to be more prevalent in some herds. Due to previously cited limitations of microbiological identification of some GPCN (Wyder et al., 2011; Werner et al., 2014), the identification of Lactococcus spp. as mastitis pathogens was unknown to these farms before the start of this study. We included a limited by-farm characterization of GPCN distribution (Tables 2 and 4), and these data are presented to describe the distribution of GPCN within and between farms. These data may also enable forming hypotheses about possible risk factors for the emergence of Lactococcus spp. as mastitis pathogens. Interestingly, some farms in our study did have Lactococcus spp. as the predominant pathogens, while others had Streptococcus spp.

In an outbreak investigation, Rodrigues et al. (2016) evaluated DNA fingerprinting profiles and concluded that multiple sources for the Lactococcus spp. were likely in that outbreak; therefore, it was less likely that a contagious component was present. Although Rodrigues et al. (2016) did not find any evidence of such a component, other pathogens previously classified as originating from environmental sources have been shown to have contagious behavior following further investigation (Munoz et al., 2007). Information on multiple herds over time is needed, in addition to longitudinal evaluation of possible farm-level risk factors that may influence predominant $\mathrm{CM}$ pathogens within the GPCN category and assessment of possible transmission modes.

\section{ACKNOWLEDGMENTS}

This study was funded by the Northern New York Agricultural Development Program. Phase 1 was executed in collaboration with Countryside Veterinary Clinic (Lowville, NY) and both phase I and phase II were in collaboration with Cornell Cooperative Extension of Jefferson and Lewis County with help from Kimberley Morrill (Chr. Hansen).

\section{REFERENCES}

Bradley, A. J., K. A. Leach, J. E. Breen, L. E. Green, and M. J. Green. 2007. Survey of the incidence and aetiology of mastitis on dairy farms in England and Wales. Vet. Rec. 160:253-257.

Devriese, L. A., J. Hommez, H. Laevens, B. Pot, P. Vandamme, and F. Haesebrouck. 1999. Identification of aesculin-hydrolyzing streptococci, lactococci, aerococci and enterococci from subclinical intramammary infections in dairy cows. Vet. Microbiol. 70:87-94.

Dohoo, I. R., and K. E. Leslie. 1991. Evaluation of changes in somatic cell counts as indicators of new intramammary infections. Prev. Vet. Med. 10:225-237.

Fortin, M., S. Messier, J. Pare, and R. Higgins. 2003. Identification of catalase-negative, non-beta-hemolytic, gram-positive cocci isolated from milk samples. J. Clin. Microbiol. 41:106-109.

Hagnestam-Nielsen, C., U. Emanuelson, B. Berglund, and E. Standberg. 2009. Relationship between somatic cell count and milk yield in different stages of lactation. J. Dairy Sci. 92:3124-3133.

Haguingan, J. M. B., M. J. N. Gordoncillo, J. A. N. Bautista, M. Hikiba, and I. G. Sarmago. 2010. Detection and identification of bacterial carriage of subclinical mastitis cases in backyard dairy cows. Philipp. J. Vet. Med. 47:21-25.

Hand, K. J., M. A. Godkin, and D. F. Kelton. 2012a. Bulk milk somatic cell penalties in herds enrolled in Dairy Herd Improvement programs. J. Dairy Sci. 95:240-242.

Hand, K. J., A. Godkin, and D. F. Kelton. 2012b. Milk production and somatic cell counts: A cow-level analysis. J. Dairy Sci. 95:1358 1362 .

Hertl, J. A., Y. H. Schukken, F. L. Welcome, L. W. Tauer, and Y. T. Grohn. 2014. Pathogen-specific effects on milk yield in repeated clinical mastitis episodes in Holstein dairy cows. J. Dairy Sci. 97:1465-1480.

Huijps, K., H. Hogeveen, T. J. Lam, and A. G. Oude Lansink. 2010. Costs and efficacy of management measures to improve udder health on Dutch dairy farms. J. Dairy Sci. 93:115-124.

Inzana, T. J., and B. Iritani. 1989. Rapid detection of group C streptococci from animals by latex agglutination. J. Clin. Microbiol. $27: 309-312$.

Jones, G. M., and J. M. Swisher. 2009. Environmental streptococcal and coliform mastitis. Publication no. 404-234. Virginia Cooperative Extension, Blacksburg, VA.

Keefe, G., J. McCarron, K. Macdonald, and M. Cameron. 2010. The scientific bases for using on-farm culture systems. Page 141-148 in Proc. Natl. Mastitis Council Reg. Mtg., Albuquerque, NM. Natl. Mastitis Council Inc., Madison, WI.

Lago, A., S. M. Godden, R. Bey, P. L. Ruegg, and K. Leslie. 2011a. The selective treatment of clinical mastitis based on on-farm culture results: I. Effects on antibiotic use, milk withholding time, 
and short-term clinical and bacteriological outcomes. J. Dairy Sci. 94:4441-4456.

Lago, A., S. M. Godden, R. Bey, P. L. Ruegg, and K. Leslie. 2011b. The selective treatment of clinical mastitis based on on-farm culture results: II. Effects on lactation performance, including clinical mastitis recurrence, somatic cell count, milk production, and cow survival. J. Dairy Sci. 94:4457-4467.

MacDonald, K., G. Keefe, J. Roy, K. Leslie, and I. Dohoo. 2011. Economic assessment of using a $3 \mathrm{M}$ petrifilm on-farm culture system for selective treatment of clinical mastitis. Pages 47-51 in International Symposium on Mastitis and Milk Quality, St. Louis, MO. Natl. Mastitis Council Inc., Madison WI.

McDougall, S. 2003. Management factors associated with the incidence of clinical mastitis over the non-lactation period and bulk tank somatic cell count during the subsequent lactation. N. Z. Vet. J. 51:63-72.

Milne, M. H., A. M. Biggs, D. C. Barrett, F. J. Young, S. Doherty, G. T. Innocent, and J. L. Fitzpatrick. 2005. Treatment of persistent intramammary infections with Streptococcus uberis in dairy cows. Vet. Rec. 157:245-250.

Munoz, M. A., F. L. Welcome, Y. H. Schukken, and R. N. Zadoks. 2007. Molecular epidemiology of two Klebsiella pneumoniae mastitis outbreaks on a dairy farm in New York State. J. Clin. Microbiol. 45:3964-3971.

National Mastitis Council. 2017. Laboratory Handbook on Bovine Mastitis. NMC, New Prague, MN.

Odierno, L., L. Calvinho, P. Traverssa, M. Lasagno, C. Bogni, and E. Reinoso. 2006. Conventional identification of Streptococcus uberis isolated from bovine mastitis in Argentinean dairy herds. J. Dairy Sci. 89:3886-3890

Olde Riekerink, R. G., H. W. Barkema, D. F. Kelton, and D. T. Scholl. 2008. Incidence rate of clinical mastitis on Canadian dairy farms. J. Dairy Sci. 91:1366-1377.

Oliveira, L., and P. L. Ruegg. 2014. Treatments of clinical mastitis occurring in cows on 51 large dairy herds in Wisconsin. J. Dairy Sci. 97:5426-5436.

Oliver, S. P., B. E. Gillespie, S. J. Headrick, H. Moorehead, P. Lunn, H. H. Downlen, D. L. Johnson, K. C. Lamar, S. T. Chester, and W. M. Moseley. 2004. Efficacy of extended ceftiofur intramammary therapy for treatment of subclinical mastitis in lactating dairy cows. J. Dairy Sci. 87:2393-2400.

Ospina, P. A., N. Rota, C. Locatelli, L. Colombo, C. Pollera, G. Giacinti, V. Bronzo, A. Casula, A. Arpinelli, V. Brossette, M. Facchi, A. Patelli, A. Ruggeri, A. Barberio, G. Potenza, D. V. Nydam, and P. Moroni. 2016. Randomized noninferiority field trial comparing 2 first-generation cephalosporin products at dry off in quarters receiving an internal teat sealant in dairy cows. J. Dairy Sci. 99:6519-6531.

Plumed-Ferrer, C., A. Barberio, R. Franklin-Guild, B. Werner, P. McDonough, J. Bennett, G. Gioia, N. Rota, F. Welcome, D. V. Nydam, and P. Moroni. 2015. Antimicrobial susceptibilities and random amplified polymorphic DNA-PCR fingerprint characterization of Lactococcus lactis ssp. lactis and Lactococcus garvieae isolated from bovine intramammary infections. J. Dairy Sci. 98:6216-6225.
Plumed-Ferrer, C., K. Uusikyla, J. Korhonen, and A. von Wright. 2013. Characterization of Lactococcus lactis isolates from bovine mastitis. Vet. Microbiol. 167:592-599.

Pol, M., and P. L. Ruegg. 2007. Relationship between antimicrobial drug usage and antimicrobial susceptibility of gram-positive mastitis pathogens. J. Dairy Sci. 90:262-273.

Raemy, A., M. Meylan, S. Casati, V. Gaia, B. Berchtold, R. Boss, A. Wyder, and H. U. Graber. 2013. Phenotypic and genotypic identification of streptococci and related bacteria isolated from bovine intramammary infections. Acta Vet. Scand. 55:53.

Randall, L. P., F. Lemma, M. Koylass, J. Rogers, R. D. Ayling, D. Worth, M. Klita, A. Steventon, K. Line, P. Wragg, J. Muchowski, M. Kostrzewa, and M. A. Whatmore. 2015. Evaluation of MALDIToF as a method for the identification of bacteria in the veterinary diagnostic laboratory. Res. Vet. Sci. 101:42-49.

Rodrigues, M. X., S. F. Lima, C. H. Higgins, S. G. Canniatti-Brazaca, and R. C. Bicalho. 2016. The Lactococcus genus as a potential emerging mastitis pathogen group: A report on an outbreak investigation. J. Dairy Sci. 99:9864-9874.

Rollin, E. K. C. Dhuyvetter, and M. W. Overton. 2015. The cost of clinical mastitis in the first 30 days of lactation: An economic modeling tool. Prev. Vet. Med. 122:257-264.

Shum, L. W., C. S. McConnel, A. A. Gunn, and J. K. House. 2009. Environmental mastitis in intensive high-producing dairy herds in New South Wales. Aust. Vet. J. 87:469-475.

Todhunter, D. A., K. L. Smith, and J. S. Hogan. 1995. Environmental streptococcal intramammary infections of the bovine mammary gland. J. Dairy Sci. 78:2366-2374.

Vasquez, A. K., D. V. Nydam, M. B. Capel, B. Ceglowski, B. J. Rauch, M. J. Thomas, L. Tikofsky, R. D. Watters, S. Zuidhof, and M. J. Zurakowski. 2016. Randomized noninferiority trial comparing 2 commercial intramammary antibiotics for the treatment of nonsevere clinical mastitis in dairy cows. J. Dairy Sci. 99:8267-8281.

Vasquez, A. K., D. V. Nydam, M. B. Capel, S. Eicker, and P. D. Virkler. 2017. Clinical outcome comparison of immediate blanket treatment versus a delayed pathogen-based treatment protocol for clinical mastitis in a New York dairy herd. J. Dairy Sci. 100:2992-3003.

Verbeke, J., S. Piepers, K. Supre, and S. De Vliegher. 2014. Pathogenspecific incidence rate of clinical mastitis in Flemish dairy herds, severity, and association with herd hygiene. J. Dairy Sci. 97:69266934

Werner, B., P. Moroni, G. Gioia, L. Lavín-Alconero, A. Yousaf, M. E. Charter, B. M. Carter, J. Bennett, D. V. Nydam, F. Welcome, and Y. H. Schukken. 2014. Short communication: Genotypic and phenotypic identification of environmental streptococci and association of Lactococcus lactis ssp. lactis with intramammary infections among different dairy farms. J. Dairy Sci. 97:6964-6969.

Wyder, A. B., R. Boss, J. Naskova, T. Kaufmann, A. Steiner, and H. U. Graber. 2011. Streptococcus spp. and related bacteria: Their identification and their pathogenic potential for chronic mastitisA molecular approach. Res. Vet. Sci. 91:349-357. 